\title{
Kepemimpinan Kepala Sekolah Dalam Inovasi Pembelajaran Saintifik Religius
}

\author{
Bagus Rachmad Saputra \\ Manajemen Pendidikan Universitas Negeri Malang \\ bagusrachmad47@gmail.com \\ Imron Arifin \\ Administrasi Pendidikan Universitas Negeri Malang \\ imron.arifin@um.ac.id \\ Ahmad Yusuf Sobri \\ Administrasi Pendidikan Universitas Negeri Malang \\ ahmad.yusuf.sobri@um.ac.id
}

\begin{abstract}
The role of the principal as a leader is certainly needed in learning activities at school. The role of the principal will lead many teachers to implement learning patterns that are in accordance with the vision, mission, and standards set by the school. This study aims to describe the role of the principal's leadership in innovating religious scientific learning with an integrated model which combines scientific learning with Islamic-based religious learning. The research method used in this study is qualitative multi-site study approach, to find similarities in both sites through interviews, observation, and documentation study. The data was analyzed using a constant comparative analysis approach. The results of the research are (1) the form of learning leadership applied in schools in the implementation of religious scientific learning, (2) the principal's innovation in implementing religious scientific-based learning, (3) the community's support for schools in religious scientific learning.
\end{abstract}

Keywords: Leadership, Headmaster, Learning, Scientific, Religious

\section{Article Info}

Received date: 3 Oktober 2020

Revised date: 19 Mei 2021

Accepted date: 21 Juni 2021

\section{PENDAHULUAN}

Peran kepala sekolah dalam aktivitas pembelajaran dapat dikatakan memiliki peran yang tidak bisa dikesampingkan. Meskipun dalam praktiknya kepala sekolah tidak terlibat langsung dalam aktivitas pembelajaran di kelas. Tetapi kepala sekolah memiliki peranan penting dalam membimbing, membina, dan memberi pengaruh terhadap pendidik untuk dapat melaksanakan aktivitas pembelajaran di kelas secara efektif. Peran sebagai pemimpin merupakan kunci bagi kepala sekolah untuk mengarahkan aktivitas pembelajaran sesuai dengan apa yang diharapkan oleh sekolah itu sendiri yang berlandasakan pada peraturan dan kurikulum yang berlaku.

Kepala sekolah sebagai seorang pemimpin menjadi kunci keberhasilan dari aktivitas pengelolaan di lembaga pendidikan yang ia pimpin. Dimana kepala sekolah memiliki pengaruh untuk menggerakkan orangorang yang ada disekitarnya untuk bergerak 
menuju tujuan yang telah ditetapkan. Dalam hal ini (Stogdill, 1974) menyebut kepemimpinan sebagai there are almost as many definitions of leadership as there are person who have attempted to define the concept. Dimana kepemimpinan memiliki beragam definisi tergantung dari bagaimana seorang pemimpin memahami perannya dan juga cara yang diterapkan untuk menggerakkan orang-orang disekitarnya yang bisa jadi antar individu memiliki cara yang berbeda karena dipengaruhi oleh beberapa faktor. Faktor tersebut antara lain pengetahuan dan pengalaman yang telah diperoleh.

Sementara (Kippenberger, 2002) mendefinisikan kepemimpinan adalah sebuah fakta dari proses yang dilakukan oleh seorang pemimpin untuk meyakinkan orang-orang disekitarnya agar memiliki motivasi dan inisiatif dalam bekerjasama sebagai bentuk usaha mencapai tujuan yang telah disepakati bersama. Hal senada juga disampaikan oleh (Robbins, 1991) bahwa kepemimpinan adalah suatu keterampilan atau kemampuan individu yang dimiliki oleh seorang pemimpin dalam memberi pengaruh serta mengarahkan orangorang yang berada dalam satu kelompok yang sama untuk mencapai tujuan.

Sementara perihal kaitannya dalam aktivitas pembelajaran yang dilakukan di sekolah. Kepemimpinan pembelajaran yang diterapkan oleh kepala sekolah secara konsep merupakan sebagai bentuk perlakuan atau tindakan yang dilakukan oleh kepala sekolah dalam menjalankan perannya sebagai leader untuk menciptakan lingkungan belajar yang kondusif serta produktif bagi guru. Dimana tujuannya adalah peningkatan prestasi belajar peserta didik (Hallinger, 2005; Miroj et al., 2020; Stewart, 2006). Dimana peran kepala sekolah begitu berpengaruh terhadap upaya peningkatan hasil belajar peserta didik terutama dalam hal pengambilan keputusan kebijakan dan strategi sekolah dalam meningkatkan prestasi belajar peserta didik, pembinaan profesional guru, serta pengondisian sarana dan prasarana pendukung kegitan pembelajaran serta lingkungan belajar yang kondusif (Blase \& Blase, 2000; Fowler \& Walter, 2003; Robinson et al., 2008).

Peran kepala sekolah sebagai pemimpin pembelajaran perlu bekerjasama dengan pendidik agar program pembelajaran di sekolah dapat terlaksana dengan baik. Dimana kepala sekola memberi motivasi, pembinaan, dan juga memberikan pengaruh agar pendidik dapat melaksanak pembelajaran di kelas dengan baik (Arifin, I., Juharyanto, Mustiningsih, \& Taufiq, 2018; Arifin, 2009; Herawan, 2017)

Peran tersebut dibutuhkan dalam aktivitas pembelajaran di sekolah. Tidak terkecuali di sekolah yang memadukan pembelajaran saintifik dengan religius dalam bentuk sekolah islam terpadu. Tentu tantangan akan lebih kompleks, dimana kepala sekolah diharapkan mampu menjadi seorang pemimpin handal dalam memberikan arahan, pemahaman, dan juga pembinaan tentang bagaimana praktik penerapan model pembelajaran berbasis saintifik religius.

Melalui pengarahan, pemahaman, dan juga pembinaan yang diberikan akan membantu pendidik dalam mengimplementasikan model pembelajaran saintifik religius yang tentunya tidak mudah. Pendidik diharapkan mampu menggali dan juga mengaitkan nilai-nilai spiritual religius ke dalam materi pembelajaran yang sifatnya saintifik(Riyanta, 2016; Veronika, 2017). Tentu membutuhkan peran kepala sekolah dalam memberikan masukan tentang hal-hal apa saja yang diperlukan oleh pendidik dalam mengimplementasikan model pembelajaran saintifik religius.

Tentu kepala sekolah perlu melakukan upaya-upaya yang konkret untuk membantu pendidik. Seperti mengadakan seminar, workshop, atau bahkan bekerjasama dengan pihak eksternal dalam melakukan pembinaan terhadap guru agar secara konsep dan praktik, mereka paham akan pembelajaran saintifik 
religius. Selain sebagai leader dan manager dalam konteks religius. Kepala sekolah tentunya diharapkan menjadi suri tauladan bagi warga sekolah. Kepala sekolah diharapkan mampu menjalin komunikasi yang baik dengan masyarakat sebagai pengguna jasa dari layanan pendidikan yang ditawarkan oleh sekolah. Oleh karena itu peran kepala sekolah sebagai pemimpin pembelajaran dibutuhkan dalam upaya peningkatan kualitas pembelajaran di sekolah yang memadukan pembelajaran saintifik dan pembelajaran spiritual religius.

\section{METODE PENELITIAN}

Penelitian ini menggunakan pendekatan penelitian kualitatif studi multi situs. Peneliti secara natural memotret setiap peristiwa yang ada di kedua situs. Kedua situs yang diteliti yakni SDIT Baitul Izzah dan SDI Plus Baitul Ikhlas. Kedua sekolah memiliki ciri yang sama yakni sebagai sekolah dasar berbasis islam terpadu yang menerapkan model pembelajaran saintifik religius.

Metode yang digunakan dalam menggali informasi dikedua situs tersebut yakni wawancara partisipatif, pengamatan mendalam, dan studi dokumentasi(Sugiyono, 2018; Ulfatin, 2014). Peneliti melakukan wawancara dengan kedua kepala sekolah sebagai informan kunci yang dirasa memiliki banyak informasi tentang masalah yang sedang diteliti oleh penulis. Kemudian peneliti melakukan wawancara dengan guru dan komite sekolah untuk menggali informasi lebih dalam lagi dan memverifikasi informasi yang telah diberikan oleh kepala sekolah sebelumnya.

Kemudian melakukan pengamatan terhadap aktivitas pembelajaran di sekolah dan melihat serta mempelajari dokumen-dokumen yang berkaitan dengan aktivitas pembelajaran di sekolah. Aktivitas tersebut dicatat dan direkam dalam bentuk catatan lapangan dan transkrip wawancara. Kemudian data yang diperoleh dianalisis melalui analisis komparatif konstan guna menemukan persamaan model pembelajaran di kedua sekolah tersebut. Keabsahan data diuji melalui trianggulasi teknik dan narasumber. Kemudian data yang sudah dikatakan valid disajikan dalam bentuk artikel ilmiah(Sugiyono, 2018).

\section{HASIL PENELITIAN DAN PEMBAHASAN}

Hasil dari penelitian yang dilakukan oleh peneliti di kedua situs. Baik di SDIT Baitul Izzah dan SDI Plus Baitul Ikhlas ditemukan persamaan pada program pembelajaran saintifik religius. Kedua sekolah mengimplementasikan pendidikan saintifik dengan mengaitkan dengan nilai-nilai spiritual religius yang berdasarkan ajaran kitab suci AlQur'an dan hadist. Selain itu, temuan lainnya dikedua sekolah sama-sama mengimplementasikan pembelajaran berbasis religius dengan strategi pembiasaan seperti sholat dhuha berjamaah dan mengaji Al-Qur'an bersama.

Temuan pada fokus pertama tentang kepemimpinan pembelajaran yang diterapkan di sekolah. Kedua kepala sekolah memiliki pola kepemimpinan yang sama dalam membina guru untuk meningkatkan kemampuan mereka dalam implementasi pembelajaran saintifik religius. Strategi yang digunakan adalah pembiasaan dan kerja sama dengan pihak eksternal.

Di SDIT Baitul Izzah menerapkan seleksi ketat bagi calon guru, selain paham tentang materi pelajaran yang akan diampu mereka dituntut memiliki pemahaman agama yang kuat dalam hal mengaji dan memaknai tafsir sebuah hadist, memadukan kurikulum nasional dengan kurikulum yang disusun sendiri oleh sekolah, menggunakan tiga bahasa pengantar dalam pelajaran yakni bahasa Arab, Bahasa Inggris, dan Bahasa Indonesia, ada tiga buku pegangan yang digunakan oleh guru dan disusun sendiri oleh sekolah yakni buku bahasa arab, fiqih, dan siroh. Serta program lainnya tilawah dan hafidz Al-Qur'an. 
Sementara di SDI Plus Baitul Ikhlas dalam proses pembelajaran, dilaksanakan secara terpisah antara pembelajaran umum dan pembelajaran agama atau relius. Setelah melaksanakan pembelajaran umum, peserta didik akan mengikuti pembinaan kerohanian melalui metode tilawati. Penekananan nilainilai religius dikaitkan dengan praktik kehidupan sehari-hari melalu pembiasaan seperti jujur, sopan, santun, dan mengikuti kegiatan pembelajaran dengan tertib. Pada aspek inovasi kepala sekolah dalam mengimplementasikan pembelajaran berbasis saintifik religius.

Kedua sekolah memiliki metode yang sama yakni bekerja dengan pihak eksternal. SDIT Baitul Izzah bekerjasama dengan pihak eksternal untuk metode mengaji peserta didik dengan metode UMMI. Sementara aspek pembelajaran bekerja sama dengan ICP untuk program kelas internasional dengan kurikulum bahasa inggris berbasis Cambridge. Sementara SDI Plus Baitul Ikhlas bekerjasama dengan pondok pesantren di Tanjunganom, Nganjuk untuk penerapan metode belajar tilawati.

Pada aspek daya dukung masyarakat, kedua sekolah didukung penuh oleh masyarakat terutama masyarakat yang menginginkan putra putrinya tidak hanya cakap secara intelektual namun juga cakap secara akhlak. SDIT Baitul Izzah cenderung lebih diminati oleh masyarakat karena lokasinya yang berada di jalan nasional dan berada di pusat kota Kabupaten Nganjuk. Selain itu juga menjadi sekolah pertama yang memadukan pendidikan saintifik dengan pendidikan agama atau religius.

Sementara SDI Plus Baitul Ikhlas lebih diminati oleh masyarakat dengan basis pondok pesantren karena sekolah menjalin kerjasama dengan salah satu pondok pesantren sehingga program yang ditawarkan sekolah diminati oleh masyarakat yang menginginkan model pembelajaran seperti pondok pesantren.
Kepemimpinan Pembelajaran Yang Diterapkan Di Sekolah Dalam Implementasi Pembelajaran Saintifik Religius

Kepemimpinan yang diterapkan oleh kepala sekolah merupakan satu bentuk otoritas wewenang yang diberikan kepada kepala sekolah untuk mengatur dan mengkondisikan sekolah sebagaimana visi dan misi sekolah tersebut. Melalui wewenang yang diberikan kepala sekolah dapat menerapkan model kepemimpinan yang dirasa cocok bagi upaya sekolah mencapai visi dan misi sekolah. Ada banyak faktor yang mempengaruhi dari pola atau gaya kepemimpinan yang diterapkan oleh kepala sekolah. Faktor tersebut antara lain pengalaman dan juga pemahaman kepala sekolah akan konsep kepemimpinan yang ideal dalam mengelola sekolah seperti apa.

Sementara pada aktivitas pembelajaran, kepala sekolah akan cenderung mengaplikasikan pengalamannya selama menjadi guru(Hallinger et al., 2015).

Seperti apa pola pembelajaran yang efektif dan kemudian bagaimana cara menerjemahkan isi kurikulum ke dalam aktivitas pemebelajaran di sekolah. Kepala sekolah akan berkutat dengan hal tersebut sebagai bentuk dari kepemimpinan pembelajaran(Martinez, 2014; Sim, 2011). Kepala sekolah beorrientasi pada kualitas pembelajaran, prestasi peserta didik, dan juga peningkatan kualitas guru dalam mengajar merupakan serangkaian kegiatan kepala sekolah dalam penerapan kepemimpinan pembelajaran.

Pada kedua sekolah baik SDIT Baitul Izzah maupun SDI Plus Baitul Ikhlas memiliki gaya kepemimpinan pembelajaran yang dapat dikatakan hampir sama. Kedua kepala sekolah berorientasi pada hasil belajar peserta didik tanpa mengabaikan proses dengan melakukan pembinaan terhadap guru secara berkelanjutan. Kedua kepala sekolah menyadari untuk mencapai hasil belajar yang diinginkan maka harus diimbangi dengan proses pembinaan 
yang baik. Termasuk melibatkan pihak eksternal dalam peningkatan kualitas kinerja guru dalam mengajar.

Sebagai sekolah yang beriklim religius, kepala sekolah menekankan internalisasi nilainilai spiritual religius harus mampu diaplikasikan dalam aktivitas pembelajaran. Hal tersebut menjadi identitas dari sekolah dan merupakan branding yang ditawarkan kepada masyarakat. Sehingga guru dituntut tidak hanya cakap dalam menguasai bidang mata pelajaran yang diampu namun juga memiliki kecakapan tentang ajaran agama sebagai dasar dari nilainilai religius yang akan diinternalisasikan kepada peserta didik(Sobri, 2015).

Guru diharapkan mampu mengaitkan antara materi pembelajaran dengan kehidupan sehari-hari melalui pandangan agama tentang materi yang sedang diajarkan. Tugas guru bukan hanya sekedar peserta didik mampu menguasai materi pembelajaran dengan hasil akhir yang memuaskan(Dr. I Gusti Ketut Arya Sunu, 2014; Herawan, 2017; Iskandar, 2013; Wibowo, 2017). Namun lebih dari itu, guru diharapkan mampu menjadi teladan sekaligus rujukan bagi peserta didik dalam memahami ajaran agama sekaligus bagaimana mereka bisa bersikap sesuai dengan nilai dan norma di masyarakat yang terkandung dalam ajaran agama. Hak itu merupakan tujuan dari sekolah yang mendidik bukan hanya cakap secara intelektual namun juga memiliki akhlak yang mulia.

\section{Inovasi Kepala Sekolah Dalam Mengimplementasikan Pembelajaran Berbasis Saintifik Religius}

Inovasi pembelajaran merupakan hal yang penting dalam upaya menerapkan pembelajaran saintifik religius. Inovasi berkaitan dengan seperti apa strategi pembelajaran yang akan diterapkan oleh guru, bahan ajar pendukung seperti apa, kemudian bagaimana cara memadukan antara pemebelajaran umum berbasis sains dengan nilai-nilai religius yang terdapat dalam ajaran agama melalui kitab suci dan hadist(Drianah, 2017; Riyanta, 2016; Sobri, 2015). Tentu kepemimpinan kepala sekolah menjadi penting dalam upaya menentukan seperti apa bentuk inovasi yang akan dilakukan. Termasuk pengambilan keputusan yang dilakukan kepala sekolah karena berkaitan dengan seperti apa arah pembelajaran yang diterapkan di sekolah.

Peran kepala sekolah juga diperlukan dalam membina guru agar guru dapat memahami konsep pembelajaran saintifik religus seperti apa dan mampu melakukan inovasi-inovasi dalam mengajar yang sesuai dengan konsep saintifik religius. Tentunya guru harus diberi kebebasan untuk menentukan strategi pembelajaran nya seperti apa. Namun disisi lain kepala sekolah juga perlu melakukan kontrol terhadap aktivitas pembelajaran yang diterapakan oleh guru di sekolah(Riyanta, 2016; Zhou, 2014).

Kedua sekolah memiliki inovasi yang hampir sama yakni strategi pembiasaan untuk beribadah berjamaah bagi peserta didik sebelum aktivitas pembelajaran dimulai. Kemudian kedua sekolah juga melibatkan pihak eksternal dalam peningkatan kualitas mutu pembelajaran di sekolah. Di SDIT Baitul Izzah, sekolah menerapakan pola pembelajaran dengan pengantar tiga bahasa yakni Bahasa Indonesia, Bahasa Inggris, dan Bahasa Arab. Pembelajaran juga dipadukan dengan kajian tentang agama Islam, setelah belajar mata pelajaran umum. Peserta didik akan diajarkan tentang kajian-kajian agama Islam seperti tilawah, fiqih, dan sejarah Islam atau sirrah. Kemudian untuk pengantar bahasa asing, sekolah bekerjasama dengan ahli bahasa inggris dan arab, untuk bahasa inggris, sekolah mengacu pada kurikulum Cambridge. Oleh karena itu sekolah bekerjasama dengan lembaga yang memiliki lisensi untuk membantu guru dalam memahami bahasa inggris dan mampu menerapkannya dalam aktivitas pembelajaran di kelas(Ahmad et al., 2018; Arifin, 2009; Azhar, 2019). 
Sementara di SDI Plus Baitul Ikhlas juga menekankan pada strategi pembiasaan pada peserta didik melalui kegiatan beribadah bersama. Pola pembelajaran yang diterapkan sama seperti pada sekolah umumnya yakni menekankan pada pemahaman konsep dan praktik dalam materi pelajaran yang disampaikan oleh guru. Setelah kegiatan pembelajaran secara umum selesai. Aktivitas belajar dilanjutkan dengan pembelajaran agama. Pendekatan yang digunakan adalah model pembelajaran agama seperti di pondok pesantren. Bentuknya pembelajaran kitab kuning, tilawah, dan juga hafalan juz dalam kitab suci Al-qur'an. Kepala sekolah bekerjasama dengan pondok pesantren untuk membina guru agar guru dapat mengimplementasikan pola pembelajaran seperti di pondok pesantren di sekolah.

\section{Daya Dukung Masyarakat Terhadap Sekolah Dalam Pembelajaran Saintifik Religius}

Daya dukung masyarakat merupakan aspek yang tidak dapat diabaikan dalam pengelolaan sekolah. Kepala sekolah diharapkan mampu menjalin komunikasi yang aktif dengan masyarakat. Pelibatan peran serta masyarakat sebagai pengguna jasa yang ditawarkan tentu memiliki peranan yang penting dalam membantu kepala sekolah untuk merumuskan kebijakan yang dirasa tepat dan sesuai dengan kebutuhan masyarakat.

Pelibatan peran serta masyarakat akan menjadi bahan bagi kepala sekolah untuk menentukan seperti apa strategi pembelajaran yang tepat untuk memenuhi kebutuhan masyarakat. Kebutuhan masyarakat sebagai pengguna lulusan tentunya harus diakomodir, sehingga program-program yang telah disusun oleh sekolah sesuai dengan kebutuhan masyarakat(Aas \& Paulsen, 2019; Hallinger et al., 2015; Haynes, 2013). Salah satunya kebutuhan masyarakat akan konsep pembelajaran yang memadukan pembelajaran umum seperti saintifik atau sosial yang dipadukan dengan pembelajaran agama. Tentunya kepala sekolah perlu melihat hal tersebut sebagai sebuah peluang untuk mengembangkan pembelajaran saintik religius guna mengakomodir kebutuhan masyarakat.

Masyarakat menjadi daya dukung bagi sekolah baik secara materi melalui pembiayaan pendidikan maupun non materi seperti sumbangsih pemikiran untuk program-program yang akan dilaksanakan oleh sekolah. Baik SDIT Baitul Izzah maupun SDI Plus Baitul Ikhlas, kedua sekolah tersebut menggandeng masyarakat sebagai mitra kerja. Baik melalui komite sekolah maupun melalui lembaga lain sebagai mitra kerja.

Sekolah bekerjasama dengan komite dalam aspek pengembangan sekolah sementara disisi lain sekolah bekerjasama dengan lembaga lain dalam upaya mengembangkan pembelajaran di sekolah seperti mengaji dengan metode UMMI dan program pembelajaran berbahasa asing(Hadi HM, 2012; Usman \& Eko Raharjo, 2013). Sebaliknya masyarakat juga mendukung program-program sekolah terutama pada program pembelajaran saintifik religius karena lulusan dari SDIT Baitul Izzah maupun SDI Plus Baitul Ikhlas dirasa memiliki kecakapan intelektual dan spiritual sesuai dengan yang diharapkan sekolah pada masyarakat.

\section{SIMPULAN DAN SARAN}

\section{Simpulan}

Kepemimpinan pembelajaran yang diterapkan adalah dengan melakukan pembinaan kepada guru sebagai bentuk dari wewenang kepala sekolah sebagai pemimpin di sekolah. Melalui pembinaan tersebut, kepala sekolah menginternalisasi nilai-nilai spiritual ke dalam aktivitas pembelajaran saintifik religius dengan memadukan materi pembelajaran secara umum lalu dikaitkan dengan pembelajaran spiritual religius dari ajaran-ajaran agama Islam. Inovasi pembelajaran yang dilakukan oleh kepala 
sekolah adalah melakukan modifikasi kurikulum nasional dengan kurikulum lokal yang ada di sekolah tanpa menghilangkan esensi dari standar proses, standar isi, dan standar penilaian yang hendak dicapai. Melibatkan pihak eksternal dalam mengembangkan inovasi pembelajaran saintifik religius yang berwawasan global seperti pelibatan tutor bahasa asing, baik Bahasa Inggris dan Bahasa Arab. Pembelajaran keislaman seperti siroh sejarah tentang perkembangan Islam, tilawah, tahfidz yang diharapkan peserta didik dapat memiliki karakter unggul secara intelektual dan adab secara akhlak. Pelibatan masyarakat sebagai daya dukung sekolah dalam mengembangkan program pembelajaran saintifik religius di sekolah melalui forum komunikasi yang dibangun oleh sekolah dan juga kerja sama antara sekolah dengan masyarakat dalam upaya pengembangan sekolah.

\section{Saran}

Kepala sekolah baik di SDIT Baitul Izzah maupun SDI Plus Baitul Ikhlas Nganjuk untuk aktif membina guru untuk meningkatkan kualitas pembelajaran di sekolah sebagai perannya seorang leader di sekolah. Dengan pengaruh yang diberikan, kepala sekolah dapat mengarahkan guru untuk mengembangkan kualitas pembelajaran di sekolah.

\section{DAFTAR RUJUKAN}

Aas, M., \& Paulsen, J. M. (2019). National strategy for supporting school principal's instructional leadership: A Scandinavian approach. Journal of Educational Administration. https://doi.org/10.1108/JEA-09-20180168

Ahmad, K., Harahap, H., Nasution, W. N., Program, M., \& Islam, P. (2018). Inovasi Pembelajaran Pendidikan Agama Islam ( Pai ) Di Sekolah Dasar Negeri 097523 Perumnas Batu Vi
Kecamatan Siantar Kabupaten Simalungun. Edu Riligia, 2(2), 275290.

Arifin, I., Juharyanto, Mustiningsih, \& Taufiq, A. (2018). Islamic Crash Course as a Leadership Strategy of School Principals in Strengthening School Organizational Culture. SAGE Open, 8(3). $\quad$ https://doi.org/https://doi. org/10.1177/2158244018799849

Arifin, I. (2009). Kepemimpinan Kepala PAUD Dalam Mengimplementasikan Pembelajaran Sentra Studi Kasus PAUD/KB Unggulan Nasional Anak Saleh Malang. Aditya Media.

Azhar, A. (2019). Kepemimpinan Kepala Madrasah dalam Meningkatkan Mutu Pendidikan di Madrasah Tsanawiyah Satu Atap Mikrajussibyan NW Selanglet Desa Penujak Kecamatan Praya Barat Kabupaten Lombok Tengah. MANAZHIM. https://doi.org/10.36088/manazhim.v1i 1.172

Blase, J., \& Blase, J. (2000). Effective instructional leadership. Journal of Educational Administration. https://doi.org/10.1108/0957823001032 0082

Dr. I Gusti Ketut Arya Sunu, M. (2014). Kontribusi Perilaku Kepemimpinan Kepala Sekolah, Iklim Sekolah, Dan Motivasi Berprestasi Terhadap Kualitas Pengelolaan Pembelajaran Para Guru Sekolah Dasar Se-Gugus I Kecamatan Karangasem. Jurnal Administrasi Pendidikan.

https://doi.org/10.23887/japi.v5i1.1456

Drianah, D. (2017). Strategi Pembelajaran Pendidikan Agama Islam dan Budi Pekerti melalui Joyfull and Meaningful Learning di Sekolah Dasar. Jurnal 
Kependidikan.

https://doi.org/10.24090/jk.v5i2.2087

Fowler, C. S., \& Walter, S. (2003). Instructional leadership. In College and Research Libraries News. https://doi.org/10.4135/9781483394268 . $\mathrm{n} 2$

Hadi HM, S. (2012). Kepemimpinan Spiritual Solusi Mengatasi Krisis Kepemimpinan Pendidikan Islam. Lisan Al-Hal.

Hallinger, P. (2005). Instructional Leadership and the School Principal: A Passing Fancy that Refuses to Fade Away. Leadership and Policy in Schools. https://doi.org/10.1080/1570076050024 4793

Hallinger, P., Wang, W. C., Chen, C. W., \& Li, D. (2015). Assessing instructional leadership with the principal instructional management rating scale. In Assessing Instructional Leadership with the Principal Instructional Management Rating Scale. https://doi.org/10.1007/978-3-31915533-3

Haynes, J. S. (2013). School-level autonomy: Who participate and who benefits. In ProQuest Dissertations and Theses.

Herawan, E. (2017). Kinerja Kepala Sekolah Sebagai Instructional Leader. Pedagogia Jurnal Ilmu Pendidikan. https://doi.org/10.17509/pedagogia.v13 i3.6002

Iskandar, U. (2013). Kepemimpinan Kepala Sekolah Dalam Peningkatan Kinerja Guru. Jurnal Visi Ilmu Pendidikan.

Kippenberger, T. (2002). Leadership Styles. Capstone Publishing.

Martinez, R. (2014). School-based change in the era of high accountability and low autonomy. In International Journal of Educational Organization and
Leadership.

https://doi.org/10.18848/2329-

1656/CGP/v20i03/48482

Miroj, A. N., Saputra, B. R., \& Gunawan, I. (2020). Principal Learning Leadership Tips Managing Learning in Schools. https://doi.org/10.2991/assehr.k.201204 .012

Riyanta, T. (2016). Mengembangkan Budaya Mutu Sekolah Melalui Kepemimpinan Transformasional. Jurnal Manajemen Pendidikan UNY.

Robbins, S. (1991). Organizations Behavior: Concept, Controversies, Application. Prentice Hall Inc.

Robinson, V. M. J., Lloyd, C. A., \& Rowe, K. J. (2008). The impact of leadership on student outcomes: An analysis of the differential effects of leadership types. Educational Administration Quarterly. https://doi.org/10.1177/0013161X0832 1509

Sim, Q. (2011). Instructional leadership among principals of secondary schools in Malaysia. International Research Journals Full, 2(December), 17841800.

Sobri, A. Y. (2015). Manajemen Pendidikan Karakter Berbasis Religi Di Sekolah Dasar. Jurnal Sekolah Dasar, 24(1).

Stewart, J. (2006). Instructional and Transformational Leadership: Burns, Bass and Leithwoood. Journal of Educational Administration.

Stogdill, R. (1974). Handbook of Leadership. The Free Press.

Sugiyono. (2018). Metode Penelitian Kualitatif (3rd ed.). Alfabeta.

Ulfatin, N. (2014). Metode Penelitian Kualitatif Di Bidang Pendidikan: Teori dan Aplikasinya. Bayu Media. 
Usman, H., \& Eko Raharjo, N. (2013). Strategi Kepemimpinan Pembelajaran Menyongsong Implementasi Kurikulum 2013. Jurnal Cakrawala Pendidikan. https://doi.org/10.21831/cp.v5i1.1253

Veronika, P. (2017). Implementasi Pembelajaran Bahasa Jawa (Materi Tembang Dolanan) Berbasis Pendidikan Karakter Religius Dalam Kurikulum 2013. El-HARAKAH (TERAKREDITASI). https://doi.org/10.18860/el.v19i1.3929

Wibowo, U. B. (2017). Kepemimpinan (Untuk) Pembelajaran: Jembatan Untuk
Memperkuat Pembentukan Karakter. Jurnal Pembangunan Pendidikan: Fondasi Dan Aplikasi. https://doi.org/10.21831/jppfa.v4i2.124 25

Zhou, Y. (2014). The Relationship Between School Organizational Characteristics and Reliance on Out-of-Field Teachers in Mathematics and Science: CrossNational Evidence from TALIS 2008. Asia-Pacific Education Researcher. https://doi.org/10.1007/s40299-0130123-8 